\title{
Gaps between calcium recommendations to prevent pre-eclampsia and current intakes in one hospital in Argentina
}

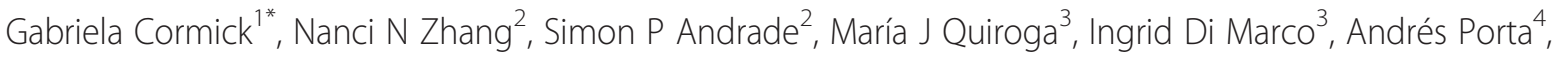
Fernando Althabe ${ }^{1}$ and José M Belizán ${ }^{1}$

\begin{abstract}
Background: Hypertensive disorders are a major cause of maternal mortality. In Latin America and the Caribbean, pre-eclampsia accounts for approximately one in every four maternal deaths. The World Health Organization recommends calcium supplementation during pregnancy for the prevention and treatment of pre-eclampsia and eclampsia in locations where dietary calcium intake is low. Calcium intake in Argentina is reported to be below WHO recommended levels; however, calcium intake from supplements and water has not been fully evaluated. The objective of this study was to evaluate calcium intake from supplements and water in a group of pregnant women.

Methods: This cross-sectional study was conducted at a maternity hospital in the city of Buenos Aires, Argentina. Questionnaires were verbally administered to women attending a routine antenatal care visit. Participants were 18 years of age or older and in their third trimester of pregnancy. Participants were first interviewed to evaluate nutritional supplement consumption and a subgroup was invited to undergo a 24-hour dietary recall.

Results: 137 women meeting inclusion criteria consented to participate. The average participant age was 27 years $(\mathrm{SD} \pm 5.9$ ), and all resided in an urban setting. None of the subjects took calcium supplements specifically, although 24 (17\%) recalled taking supplements or antacids which contributed to their calcium intake. Mean calcium intake was $663 \mathrm{mg}$ SD \pm 389 for those women completing the 24 -hour dietary recall,. This value increased to $706 \mathrm{mg}$ SD \pm 387 upon considering water intake and measuring chemical composition of water from the areas where women lived at the time of the interview and was further increased to $719 \mathrm{mg}$ (SD \pm 392 ) when calcium from supplements was taken into consideration.

Conclusions: None of the subjects were consuming calcium supplements. Taking into account the low calcium intake in this population, diverse strategies would be required to comply with recommendations.
\end{abstract}

Keywords: Perinatal, Prenatal, Healthcare, Pre-eclampsia, Argentina, Calcium intake, Maternal nutrition

\section{Background}

Hypertensive disorders account for $18 \%$ of all maternal death world-wide with an estimated 62,000 to 77,000 deaths annually [1]. Pre-eclampsia, a gestational disorder defined as hypertension accompanied by proteinuria, is a major cause of maternal death in Latin America and the

\footnotetext{
*Correspondence: gcormick@iecs.org.ar

'Department of Mother \& Child Health Research, Institute for Clinical Effectiveness and Health Policy (IECS), Dr. Emilio Ravignani, 2024 Buenos Aires, Argentina

Full list of author information is available at the end of the article
}

Caribbean, accounting for approximately one in every four maternal deaths $[2,3]$.

The hypothesis that increased calcium intake during pregnancy reduces the risk of pre-eclampsia was first postulated during the 80s [4,5]. A systematic review of 13 randomised control trials shows that women who received calcium supplementation during pregnancy were less likely (RR: $0.45 ; 0.31-0.65$ ) to develop pre-eclampsia than women who received a placebo [2]. Further, a higher protective effect was observed among women with low basal calcium intake (less than $900 \mathrm{mg} /$ day) (RR 0.36, IC 95\% 
0.20 a 0.65). In 2011, the World Health Organization (WHO) published recommendations for the prevention and treatment of pre-eclampsia and eclampsia, and classified calcium supplementation during pregnancy as a strong recommendation with moderate evidence in areas where dietary calcium is low. However there is some degree of controversy, as systematic review also shows a marginal increase of HELLP syndrome, the hypothesis is that as calcium supplementation reduces blood pressure and delays the diagnosis and treatment of pre-eclampsia, allowing more time for the condition to progress to HELLP syndrome $[2,6]$.

Calcium intake in Argentina is below recommended levels. The National Nutrition and Health Survey (ENNyS), a nationally representative survey carried out in 2005, estimated a mean intake of $529(\mathrm{SD} \pm 389) \mathrm{mg} /$ day in pregnant women using a single 24-hr recall [7]. Intake of calcium supplements was reported by only one percent of the women of fertile age, although consumption of calcium from water and multivitamin or mineral supplements was not assessed (ENNyS 2007). Another limitation of the ENNyS survey is that a single 24-hr recall was used and not the recommended multiple pass methodology that allows the several opportunities to verify the data reported [8].

The objective of this study was to evaluate calcium supplementation in a sample of pregnant women attending a leading maternity hospital in Argentina using a multiple pass 24 -hour dietary recall questionnaire.

\section{Methods}

This cross-sectional study of pregnant women was conducted during July and August 2012 at a maternity hospital in Buenos Aires, Argentina. The Hospital Materno Infantil Ramón Sardá is a comprehensive referral maternity hospital performing around 7,000 deliveries a year, mainly serving women living in both the capital of Buenos Aires (estimated population: 3 million inhabitants) and the surrounding Greater Buenos Aires area (estimated population: 10 million inhabitants) [9].

The healthcare system has 3 sectors: the labour union insurance funds, the public sector, and the private sector [10]. Women receiving care in public hospitals in Argentina typically are identified as belonging to a lower-middle socioeconomic class. They represent around 50\% of the population, mainly by the $38 \%$ of the population who do not have formal work or cannot afford private insurance and by a fraction of those from the labour union insurance funds [9].

This study was approved by the Institutional Review Board (IRB) of Tulane University and the Ethics Committee of the Centre of Medical Education and Clinical Investigations in Buenos Aires, Argentina.

\section{Participants and procedures}

Inclusion criteria required participants to be at least 18 years of age and in their third trimester of pregnancy (at least 27 weeks of pregnancy completed). The third trimester was selected to allow subjects' recall of supplement intake during their current pregnancy.

Research personnel approached pregnant women in waiting rooms prior to the patients' prenatal appointments and assessed their eligibility. Women were informed about the objectives of the study and those electing to participate were invited to sign the informed consent and then interviewed by the previously trained hospital dietician in a quiet nearby office. All women were first interviewed using a short questionnaire to obtain demographic characteristics including: maternal education, age and area of residence, and whether they were taking supplements or medicines known to contain calcium. The dietician was provided with a list of nutritional supplements and medicines containing calcium available in the market. Women were asked about frequency and dose of the supplements and medicines and if they were following professional recommendations. The type and dose of the supplements were recorded to develop a list of supplements most frequently consumed by pregnant women, and to assess supplement intake during pregnancy in this group. For this short questionnaire, sampling was performed by convenience. Interviewers recruited all eligible women in waiting rooms until completing the sample size.

A systematic sampling technique was used to evaluate dietary calcium intake. Every fifth woman taking the short questionnaire was asked to undergo a triple pass 24-hour dietary recall developed for this study to assess the participant's nutritional intake in the previous day. After each 24-hour recall interview the dietician completed a face validity questionnaire, a subjective report evaluating if the interview recorded the food and drinks the women had consumed in the previous day.

\section{Calcium content of water}

Women undergoing the 24-hour recall were specifically asked the type and amount of water consumed. Sources mentioned included commercially bottled water and tap water. Calcium content of commercially bottled water was obtained from nutrition information labels. Piped water, samples were obtained from the areas of residence that were reported by participants in the short questionnaire and were chemically analysed. Samples were collected following instructions of the Sanitary Engineering Laboratory of the University of La Plata.

Calcium content was determined using the ethylenediamine tetra acetic acid titration method (EDTA) that detects calcium from $2 \mathrm{mg} / \mathrm{l}$ of $\mathrm{CaCO}$. This method has a relative error of $1.9 \%$ and requires $25 \mathrm{ml}$ of water of each sample [11]. 


\section{4-hour recall questionnaire}

The 24-hour recall was collected following the multiple pass methodology [12]. First, respondents were asked to report everything that they had to eat or drink on the previous day between midnight to midnight, then they were asked to report details of each food to obtain the amount consumed, and finally a review was done to prompt for items usually forgotten such as supplements, drinking water, snacks and sweets. Interviews were performed from Monday to Friday until the sample size was reached. As 24-hour recalls collect information on the previous day's intake, we were able to register intakes of Sundays as the non-typical day.

Completed questionnaires were stored securely in binders by the interviewers and subsequently collected by research staff.

\section{Data analysis}

Data was entered into Excel spreadsheets and measures of spread were calculated using SPSS Version 18.

The sample size of 135 subjects was estimated under the assumption that there were around 600 deliveries per month and that $10 \%$ of women took nutritional supplements with a $+/-4 \%$ error in the estimation, and a confidence level of $90 \%$. A study conducted in the province of Buenos Aires showed that 19\% of women interviewed after delivery reported taking vitamin or mineral supplements [13]. We estimated that $10 \%$ of women would be taking calcium supplements during the third trimester of pregnancy.

\section{Results}

A total of 304 women were screened in the waiting rooms and $188(61.8 \%)$ met the inclusion criteria, $172(91.5 \%)$ of those eligible consented to participate while $16(8.5 \%)$ refused. Of those enrolled, 137 (79.7\%) women completed the interview, but 35 (20.3\%) left before starting the interview.

Table 1 provides the demographic characteristics of women interviewed. The mean age of participants was 27 years $(\mathrm{SD} \pm 5.9)$, all women reported living in urban areas, $29(21.2 \%)$ had 7 or less years of formal education, $123(89.8 \%)$ of them did not have a health provider and 54 (39.4\%) were nulliparous.

None of the 137 women were specifically consuming calcium supplements, however 24 (17\%) were taking a supplement or a medication containing between 100 and $320 \mathrm{mg}$ of elemental calcium. 14 (10\%) reported taking supplements containing calcium, 9 (7\%) reported taking antacids and 1 reported taking both composite supplements and antacids. The supplements or medicines provided an average of $148 \mathrm{mg}$ per day for those 24 participants that consumed any of them and $25 \mathrm{mg}$ per day when averaging the amount within the 137 participants.
Table 1 Demographic information

\begin{tabular}{|c|c|c|c|}
\hline & & All woman & $\begin{array}{l}\text { Dietary } \\
\text { assessment } \\
\text { subgroup }\end{array}$ \\
\hline \multirow[t]{2}{*}{ Characteristics } & & $(n=137)$ & $(n=29)$ \\
\hline & & n (\%) & n (\%) \\
\hline \multirow[t]{3}{*}{ Age (years) } & Less than 20 & $13(9.5)$ & $7(24.1)$ \\
\hline & 20 to 34 & $109(80.0)$ & $20(69.0)$ \\
\hline & 35 and more & $15(11.0)$ & $2(6.9)$ \\
\hline \multirow[t]{5}{*}{ Country of birth } & Argentina & $69(50.4)$ & $19(65.5)$ \\
\hline & Bolivia & $36(26.3)$ & $5(17.2)$ \\
\hline & Paraguay & $18(13.1)$ & $3(10.3)$ \\
\hline & Peru & $12(8.8)$ & $2(6.9)$ \\
\hline & Other & $2(1.4)$ & $0(0)$ \\
\hline \multicolumn{4}{|l|}{ Area of residence } \\
\hline & City of Buenos Aires & $59(43.1)$ & $11(37.9)$ \\
\hline & Province of Buenos Aires & $78(56.9)$ & $18(62.1)$ \\
\hline \multirow[t]{2}{*}{ Health provider } & Labour Union & $14(10.2)$ & $4(13.8)$ \\
\hline & None & $123(89.8)$ & $25(86.2)$ \\
\hline \multirow{3}{*}{$\begin{array}{l}\text { Number } \\
\text { of children }\end{array}$} & Nulliparous & $54(39.4)$ & $16(55.2)$ \\
\hline & Multiparas & $79(57.7)$ & $13(44.8)$ \\
\hline & Missing & $4(2.9)$ & $0(0)$ \\
\hline \multirow{4}{*}{$\begin{array}{l}\text { Year in formal } \\
\text { education }\end{array}$} & 7 years or less & $29(21.2)$ & $8(27.6)$ \\
\hline & $\begin{array}{l}\text { More than } 7 \text { to } \\
\text { less than } 12 \text { years }\end{array}$ & $37(27.0)$ & $6(20.7)$ \\
\hline & 12 years & $35(25.5)$ & $6(20.7)$ \\
\hline & More than 12 years & $36(26.3)$ & $9(30.1)$ \\
\hline
\end{tabular}

\section{Calcium content of water}

All 137 women taking the short survey lived in areas supplied by water networks, however the coverage varies and can be divided in three main sectors; the city of Buenos Aires where $99 \%$ of the population is covered by water networks, the Greater Buenos Aires areas with at least $80 \%$ of the population is covered by water networks, and other Greater Buenos Aires areas with around 50\% is covered by water networks. The areas not supplied by water networks are served by local wells.

Fifty-nine (43.1\%) women resided in the city of Buenos Aires, 68 (49.6\%) came from Greater Buenos Aires with $80 \%$ coverage and $9(6.6 \%)$ women lived in areas where water networks cover around half of the population. Eleven samples of water were analysed, 8 (72.7) samples came from areas mainly covered by water network supplies and 3 samples came from wells.

Tap water from network supplies contained an average of $34 \mathrm{mg}$ of calcium per litre with a range from 25 to 88 $\mathrm{mg} / \mathrm{l}$ and that from local wells $100 \mathrm{mg}$ of calcium per litre with a range from 28 to $173 \mathrm{mg} / \mathrm{l}$. Bottled mineral water contained an average of $38 \mathrm{mg} / \mathrm{l}$ of calcium with a range from 25 to $78 \mathrm{mg} / \mathrm{l}$. 
Of the 29 women undergoing the 24-hour recall 13 (44.8) came from areas with $80 \%$ coverage, 11 (37.8\%) came from the city of Buenos Aires and 5 (17.2\%) from areas with around 50\% coverage.

\section{4 hour recall questionnaire}

The 24-hour dietary recall was administered to 29 women. The questionnaire administration took approximately 18 minutes to complete (range 9-35 minutes). Women's mean age was 24.7 years ( $\mathrm{SD} \pm 6.03$ ), with 8 individuals $(27.6 \%)$ reporting highest education level of primary school or less and $16(55.2 \%)$ were nulliparous.

Of these women that underwent the 24-hour recall, 7 (24\%) were interviewed on a Monday, thus reporting their Sunday intakes, which represents a non-typical day. The rest of the interviews were on weekdays and the day distribution was $3(10 \%)$ on Tuesdays, 5 (17\%) on Wednesdays, $10(34 \%)$ on Thursdays and 4 (14\%) on Friday.

Mean energy intake was 1874 (SD \pm 487$)$ kcal composed of $246(\mathrm{SD} \pm 76)(52 \%)$ grams of carbohydrates, 63 $(\mathrm{SD} \pm 20)(14 \%)$ grams of protein, and $71(\mathrm{SD} \pm 27)(34 \%)$ grams of fat (Table 2).

From the 29 women that finished the 24-hour recall, 9 (31\%) reported taking a calcium containing supplement or medication which provided an average of $134 \mathrm{mg}$ of calcium per day and $42 \mathrm{mg}$ if the amount was averaged by all 29 participants.

All 29 women reported drinking tap water and 13 mineral water as well. As it is difficult to assess whether the tap water consumed came from a water networks or a well, we calculated total calcium intake from tap water using mean values of water network supply only, as this type of water is available in all areas. The exact chemical composition of bottled water was used when participants provided details of the brand, otherwise the average was used. Total water intake provided in average 43 $\mathrm{mg}$ of calcium a day $(\mathrm{SD} \pm 27)$.

Mean calcium intake was $663 \mathrm{mg}(\mathrm{SD} \pm 389)$. Mean calcium intake increased to $706 \mathrm{mg}(\mathrm{SD} \pm 387)$ when calcium from water intake was included and to $719 \mathrm{mg}(\mathrm{SD} \pm 392)$ when calcium from supplements was considered.

Table 2 Energy, protein, fats, carbohydrates and calcium intake

\begin{tabular}{lccccc}
\hline & n & Minimum & Maximum & Mean & $\begin{array}{l}\text { Std. } \\
\text { deviation }\end{array}$ \\
\hline Energy (Kcal) & 29 & 844.7 & 2967.3 & 1874.2 & 487.4 \\
Protein (grams) & 29 & 37.8 & 111.0 & 63.3 & 19.8 \\
Lipids (grams) & 29 & 22.4 & 120.5 & 71.0 & 27.0 \\
Carbohydrates (grams) & 29 & 78.0 & 415.5 & 245.7 & 76.5 \\
Calcium (miligrams) & 29 & 144.6 & 1679.3 & 706.5 & 386.7 \\
\hline
\end{tabular}

Compared to what the women recalled as their usual diet, 17 reported that the amount consumed was similar to other days, 9 reported it was less and 3 that it was more than usual. Reasons for eating less included: not hungry (2), dieting (2), little food at home (1), busy (1), special occasion (1) and no reason (2). Those reporting having more than usual mentioned that the previous day was a weekend or that they had cravings. Women were also asked to compare the food reported with that prior to pregnancy; 10 women reported having a similar intake, 10 reported higher consumption and 9 reported lower consumption.

To assess the validity of the recall questionnaire, the dietician administering the interviews qualified 27 out of 2924 hour recalls as good in the way they represented women intakes, whereas 2 were qualified as poor or moderate.

\section{Discussion}

This study shows that, in a maternity hospital in Buenos Aires, there is no compliance with taking the 1,5 grams of calcium recommended by WHO guidelines for the prevention of pre-eclampsia [6]. None of the subjects took calcium supplements specifically, although 24 (17\%) of them took multivitamin supplements or antacids containing between 100 and $320 \mathrm{mg}$ of elemental calcium. We also found that in a sub-sample of this study calcium intake is below recommendations.

One advantage of this study is that evaluates calcium from supplements, medicines and water and those values were taken into account when calculating total calcium intake.

The assessment tool used in this study was a triplepass 24-hour dietary recall, a fairly common technique among nutritional studies. It is subject to less recall bias than diet histories and food frequency checklists, which rely upon a greater recall period $[14,15]$. Further, the 24recall method does not require high literacy of the respondent and minimises inter-observer differences [16]. However a single 24-hour recall does not allow estimating usual calcium intake or the percentage of inadequate nutrient intake within a population, as these values are not adjusted for within-person variability [14].

One limitation of this study is that almost 19\% of women left before starting the interview and $8 \%$ refused to participate. A small number of women were interviewed for the dietary assessment and this limits the conclusion about total calcium intake in this population.

The information in this study was similar to that shown in the ENNyS where only $1 \%$ of women of childbearing age were taking calcium supplements, although calcium supplement intake of pregnant women was not reported [7].

Although the amount of calcium in water is relatively low, it is an interesting source of calcium considering that 
water intakes are high and calcium water has a good bioavailability, similar to that of cow's milk [17]. The samples analysed in this study are representative for those areas supplied by the public water network. Further analysis is required to assess areas with wells, as calcium levels can vary significantly depending on the area. According to the samples analysed in this study, water from public networks seems to have lower calcium content than water from wells. The total calcium provided by water intake could be higher for this population, as the water network chemical composition was used for the analysis of calcium intake.

In a sub-sample of this study we found that calcium intake is below recommendations, however the value is higher than that reported by the ENNyS in 2007 [7]. This could be explained by an improvement of dietary calcium intake in the population or by the fact that women in the sub-sample were younger; the same ENNyS shows a higher intake in non-pregnant women younger than 19 years. More women in this sub-sample also consumed supplements or antacids containing calcium. This might show a different behaviour that can reflect also a difference in food patterns.

While information provided in this study is not strictly representative of the population in Argentina, women receiving care in public hospitals in Argentina represent around half of the population, 38\% of those population who do not have formal work or cannot afford private insurance and a fraction of those from the labour union insurance funds [9]. Also there is some evidence that calcium intake is low in the country and represents a nutritional problem [7]. Furthermore, a recent review of worldwide studies reporting dietary intakes of pregnant women from low and middle-income countries show consistent low calcium intakes across Asia, Africa and Latin American countries [18]. In Latin America, only Mexico and Ecuador were above the $833 \mathrm{mg}$ a day Estimated Average Requirement [19].

Despite being known for many years that adequate calcium intake prevents preeclampsia, calcium intake in this population is still low. This study shows that this group of pregnant women does not use supplements to improve their calcium intake as it is recommended by the recent $\mathrm{WHO}$ Guidelines in order to reduce the risk of having preeclampsia [6]. Similar results were shown in one large study carried out in Brazil, where 788 women with also low calcium intakes were interviewed and less than $6 \%$ of women received the prescription for calcium supplements [20].

We did not assess whether health providers at this hospital are taking action to improve maternal calcium intake such as prescribing calcium supplements or giving dietary advice. However, it seems that in low and middle-income countries there is poor adherence of women to nutritional supplements such as calcium, folic acid or iron $[18,21,22]$. Therefore, strategies to increase calcium intake should be explored and developed to improve calcium intake in this population.

\section{Conclusions}

None of the subjects were consuming calcium supplements. Taking into account the low calcium intake in this population, diverse strategies would be required to comply with recommendations.

\section{Abbreviations}

ENNyS: Encuesta Nacional de Nutrición y Salud. National Nutrition and Health Survey; WHO: World Health Organization.

\section{Competing interests}

The authors declare that they have no competing interests.

\section{Authors' contributions}

GC participated in study design, data analysis, and manuscript drafting. NZ and SA participated in study design, IRB submission, data collection/analysis, and manuscript drafting. MJQ and IDM participated in data collection and IRB submission. FA, JB and AP participated in study design, data interpretation, and manuscript drafting. All authors read and approved the final manuscript.

\section{Acknowledgements}

The authors wish to thank the contribution the Hospital Maternidad Ramón Sardá and the Laboratorio de Ingeniería Sanitaria of the National University of La Plata.

The project described was supported by Grant Number T37MD001424 from the National Center for Minority Health and Health Disparities (NCMHD).

\section{Author details}

${ }^{1}$ Department of Mother \& Child Health Research, Institute for Clinical Effectiveness and Health Policy (IECS), Dr. Emilio Ravignani, 2024 Buenos Aires, Argentina. ${ }^{2}$ School of Public Health and Tropical Medicine, Tulane University, 1440 Canal St., Ste. 2430, New Orleans, LA 70112-2705, USA. ${ }^{3}$ Hospital Materno Infantil "Ramón Sardá", Esteban de Luca 2151, 1246 Buenos Aires, Argentina. ${ }^{4}$ Laboratorio de Ingeniería Sanitaria, National University of La Plata, 47 N²00, CP1900 La Plata, Argentina.

Received: 22 January 2014 Accepted: 11 December 2014 Published: 16 December 2014

\section{References}

1. Abalos E, Cuesta C, Carroli G, Qureshi Z, Widmer M, Vogel JP, Souza JP, WHO Multicountry Survey on Maternal and Newborn Health Research Network: Pre-eclampsia, eclampsia and adverse maternal and perinatal outcomes: a secondary analysis of the World Health Organization Multicountry Survey on Maternal and Newborn Health. BJOG 2014, 121(Suppl 1):14-24.

2. Hofmeyr GJ, Lawrie TA, Atallah AN, Duley L, Torloni MR: Calcium supplementation during pregnancy for preventing hypertensive disorders and related problems. Cochrane Database Syst Rev 2014, 2:CD001059. pub4.

3. Khan KS, Wojdyla D, Say L, Gulmezoglu AM, Van Look PF: WHO analysis of causes of maternal death: a systematic review. Lancet 2006, 367:1066-1074.

4. Belizán JM, Villar J, Repke J: The relationship between calcium intake and pregnancy-induced hypertension: up-to-date evidence. Am J Obstet Gynecol 1988, 4:898-902.

5. Belizán JM, Villar J, Bergel E, del Pino A, Di Fulvio S, Galliano SV, Kattan C: Long term effect of calcium supplementation during pregnancy on the blood pressure of offspring: follow up of a randomised controlled trial. Br Med J 1997, 315:898-902.

6. World Health Organization: recommendations for prevention and treatment of pre-eclampsia and eclampsia; [http://whqlibdoc.who.int/publications/2011/ 9789241548335_eng.pdf.] 
7. Ministerio de Salud de la Nación, Argentina: Encuesta Nacional de Nutrición y Salud (ENNyS): Documento de resultados; 2007 [http://www.extensioncbc. com.ar/wp-content/uploads/ENNyS-2007.pdf]

8. Mann J, Truswel S: Essentials of human nutrition. 3rd edition. Oxford: OUP; 2007.

9. Instituto Nacional de Estadística y Censo: Censo Nacional de Población, Hogares y Viviendas, Censo del Bicentenario: Resultados definitivos; [http://www.censo2010.indec.gov.ar/archivos/censo2010_tomo1.pdf]

10. Vetter CL, Gibbons L, Bonotti A, Klein K, Belizán JM, Althabe F: Obstetric care for resident immigrant women in Argentina compared with Argentine women. Int J Gynaecol Obstet 2013, 122:140-144.

11. American Public Health Association: Part 2: Physical and aggregate properties. In Standard methods for the examination of water and wastewater. 20th edition. Edited by Clescerl LS, Greenberg AE, Eaton AD. American Water Works Association, Water Environment Federation; 1999:30-37.

12. Moshfegh AJ, Borrud LG, Perloff BP, LaComb RP: Improved method for the 24-hour dietary recall for use in national surveys. $J$ Fed Am Soc Exp Biol 1999, 13:A603.

13. Marín GH, Cañas M, Homar C, Aimetta C, Orchuela J: Taking medicine during pregnancy in females living in Buenos Aires, Argentina. Rev Salud Pública 2010, 12:722-731.

14. Rush D, Kristal AR: Methodologic studies during pregnancy: the reliability of the 24-hour dietary recall. Am J Clin Nutr 1982, 35(Suppl 5):1259-1268.

15. Dodd KW, Guenther PM, Freedman LS, Subar AF, Kipnis V, Midthune D, Tooze JA, Krebs-Smith SM: Statistical methods for estimating usual intake of nutrients and foods: a review of the theory. J Am Diet Assoc 2006, 106:1640-1650.

16. Medical Research Council: Dietary assessment - recalls; [http://dapa-toolkit. mrc.ac.uk/dietary-assessment/methods/recalls/index.html]

17. Gueguen L, Pointillart A: The bioavailability of dietary calcium. J Am Coll Nutr 2000, 19(Suppl 2):119S-136S.

18. Lee SE, Talegawkar SA, Merialdi M, Caulfield LE: Dietary intakes of women during pregnancy in low- and middle-income countries. Public Health Nutr 2013, 16:1340-1353.

19. Ross AC, Taylor CL, Yaktine AL, Institute of Medicine (US) Committee to Review Dietary Reference Intakes for Vitamin D and Calcium: Dietary reference intakes for calcium and vitamin D. Washington (DC): National Academies Press (US); 2011

20. Camargo EB, Moraes LF, Souza CM, Akutsu R, Barreto J, da Silva EM, Betrán AP, Torloni MR: Survey of calcium supplementation to prevent preeclampsia: the gap between evidence and practice in Brazil. BMC Pregnancy Childbirth 2013, 13:206.

21. Zabala R, Waisman I, Correlli M, Tobler B, Bonora L: Folic acid for neural tube defects prevention: consumption and information in fertil-age women in Centro Cuyo Region. Arch Argent Pedriatr 2008, 4:295-301.

22. Karolinski, Micone P, Mercer R, Gibbons L, Althabe F, Belizan JM: Evidencebased maternal and perinatal healthcare practices in public hospitals in Argentina. Int J Gynaecol Obstet 2009, 2:118-122.

doi:10.1186/1756-0500-7-920

Cite this article as: Cormick et al: Gaps between calcium recommendations to prevent pre-eclampsia and current intakes in one hospital in Argentina. BMC Research Notes 2014 7:920.

\section{Submit your next manuscript to BioMed Central and take full advantage of:}

- Convenient online submission

- Thorough peer review

- No space constraints or color figure charges

- Immediate publication on acceptance

- Inclusion in PubMed, CAS, Scopus and Google Scholar

- Research which is freely available for redistribution

Submit your manuscript at www.biomedcentral.com/submit 